\title{
Impacts of Photovoltaic Systems on a Brazilian Distribution Feeder using OpenDSS
}

\author{
Eduardo Mateus Costa Santos de Oliveira ${ }^{1}$, Marcelo Escobar de Oliveira ${ }^{1}$ and Luis Gustavo Wesz da \\ Silva ${ }^{1}$ \\ ${ }^{1}$ Núcleo de Pesquisas em Sistemas de Energia - NuPSE \\ Federal Institute of Education, Science and Technology of Goias - IFG \\ Campus of Itumbiara - Goias (Brazil) \\ +55 64 21035600, e-mail: edu.matexyz@gmail.com, marcelo.oliveira@ifg.edu.br, luis.gustavo@ifg.edu.br
}

\begin{abstract}
.
The growing demand for electricity, environmental concerns, renewable energy sources and improved electricity supply has created a new scenario in the global electricity sector. So, it has been necessary adjustments and reanalysis of the electrical networks, which for the most part were not built to be active networks, with distributed generation of energy. Thus, the present work proposes to analyse the behavior of the indices of losses and voltage levels of a real Brazilian feeder, which does not have details of the actual load profiles of the consumers. In this approach, different load profiles and the impacts caused by different penetration levels of distributed generators in the network will be considered. For these analysis will be used OpenDSS that has been used by companies and researchers around the world. The analysed feeder is very extensive and is located in a electric utility in the interior of Brazil and the generation assumed is the photovoltaic that has grown substantially in the country. In the results will be noted those impacts can be positives and negatives to the system.
\end{abstract}

\section{Key words.}

Real distribution feeder, photovoltaic, distributed generation, OpenDSS

\section{Introduction}

The world energy matrix is constantly being reformulated, especially with the increasing demand for electricity and the intermittence of primary energy sources, by the search for clean and renewable energy generation. It is in this sense that photovoltaic and wind farms have grown too much, structuring new models of electrical systems with the presence of distributed generation (DG). In Brazil, in 2019, DG exceeded the $1 \mathrm{GW}$ mark of installed power [1]. Distributed generation is defined as power plants, with installations connected directly to the electric distribution system or through consumer installations and can operate in parallel or in isolation [2]. For [3], DG is a power station serving a consumer or providing support for a distribution system, connected in the network at the voltage level of the distribution. In [4], distributed generation is conceptualized as generation units connected generally in the distribution network, which do not present centralized dispatch and can offer up to $100 \mathrm{MW}$.

A correct DG connection on the electrical power system allows the improvement of the network indicators, contributing to the reduction of technical losses and stability of the voltages in the nodes [5]. In addition, the DG participation diversifies the energy matrix, decentralizing demand on non-renewable energy sources. This fact contributes to the stability and quality of energy offered to the various energy sectors as industrial, commercial and residential sector. However, the unrestrained increase of DG insertion can induce negative consequences, which reflexes at the connection point of the generators with the network and in the transmission system. Such consequences occur due to reverse power flow, which is the surplus power generated at the point of connection to the network not consumed by the load. This reverse flow can be responsible for the voltage increase beyond the values allowed by the equipment, as well as for the increase of the electrical losses in the network, which directly reflects on the consumer invoice.

In this new scenario, in which the distribution networks are no longer passive with unidirectional power flow (substation towards consumer) and begin to contain active elements, such as the consumer generating their own energy, energy storage, among others, there is a need in technical, economic and regulatory issues. Thus, in recent years, the search for an intelligent distribution network, in which there is a greater communication between the components of the system, throughout the world has increased the analysis and studies in the sector and above all the discussions about the regulations. Due to the particularities of each country, discussions can take different ways. In the United States, the implementation of smart grids is motivated by such things as: giving a new impulse to the country's economy, increasing security of electricity supply and concern for the environment preservation. In European countries, perhaps the greatest motivation is environmental, seeking the large-scale insertion of renewable energy sources. In countries with a large territorial area and extensive transmission lines, such as China and Brazil, besides the environmental concern, a major motivation for the deployment of active elements in distribution networks, as distributed generators, is the reduction of electric losses.

Electrical losses are largely inherent in the supply of energy to consumers, so generators close to consumers tend to reduce the high rates that occur in the transport of energy over long distances. And also improve other indicators such as voltage levels at certain points in the electric network. However, the complexity and dynamics of the distribution networks require that analysis be re-made and technical, economic and regulatory actions should be performed. The amount 
calculation of the electric losses in a real feeder depends substantially on the quality and quantity of information that the company has of its systems, which currently represents a big problem in several electric utilities in Brazil.

In this sense, the present work proposes to analyse the electrical losses and voltage levels in a distribution system (specifically a large feeder) of a Brazilian electric utility. The analyses were realized for the one day period. Typical load curves were used because in Brazil there are still few consumers that the companies have the daily load profile.

For this analysis the Open Distribution System Simulator (OpenDSS) was used. It is a real feeder in which possible scenarios of insertion of distributed generation will be analyzed, specifically photovoltaic generators, which have grown substantially in Brazilian electrical networks.

\section{Distributed Generation}

In the world, electricity consumption is a strong indicator of the development degree in a country, as more developed nations need more and more energy for the functioning of the national industry, for example [6]. Thus, with the rise of underdeveloped countries to ever higher levels of development, the demand for electricity is also increasing too much. At the same time, with the lack of non-renewable resources in the world, coupled with environmental concerns, many countries are adopting the strategy of diversifying their energy matrix, with distributed generation. Thus, as shown in Fig. 1, photovoltaic generation as well as the various forms of distributed generation gained strength.

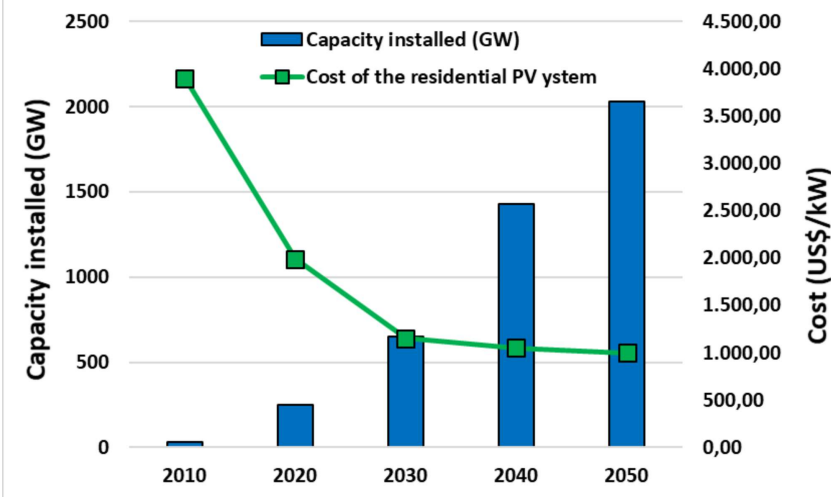

Fig. 1. Projection of installed capacity and cost of photovoltaic systems in the world [3].

Such growth is justified, according to segments of the electricity sector, by the strength of China and Taiwan in the production of photovoltaic systems which has led to the fall in the acquisition prices of the equipments [3]. However, other segments of electric sector describe a low growth rate of photovoltaic systems in the world energy matrix due to the high initial cost of acquisition, worsen by the long amortization period of the investment, as shown in Fig. 1. From the environmental perspective, which gives priority to generation based on renewable sources, photovoltaic is appropriate, because the source of driving force for electric generation is the sun, which is a clean and abundant source, and its installation does not imply environmental impacts, visual and sound [5].

The implementation of photovoltaic systems can be verified in two different ways: grid connected and isolated photovoltaic systems. The second one is when is not viable to build a network that connects the distribution system to the consumer unit, mainly due to distance reasons or natural factors. In these systems, the generated power is used by the consumer unit and gradually stored in batteries for the consumption in the instant that generation of the panels end, discarding connection with the network. In grid-connected photovoltaic systems, there is a connection between the consumer unit and the electrical system, creating situations where the excess power generated by photovoltaic systems is injected into the grid [7].

In Brazil, photovoltaic generation has been receiving subsidies that have led to high growth, especially in installed capacity, which still contrasts with the high potential that exists in the country with attention to the northeast, with an incidence of 20 to $22 \mathrm{MJ} / \mathrm{m}^{2} /$ day to be explored [6]. Photovoltaics corresponds to $1.26 \%$ of the total generation in the Brazilian energy matrix [8], and had a $40 \%$ increase in installed power from 2017 to 2018 [9]. Thus, these data are sufficient to motivate research on the impact of the connection of these photovoltaic systems to the Brazilian networks companies.

\section{OpenDSS Approach}

In 1997, with the objective of solving problems in electrical power systems, focusing on the distribution of electric energy, the Distribution System Simulator (DSS) tool was created by Electrotek Concepts. In 2004, the software was acquired by EPRI (Electric Power Research Institute) being named OpenDSS.

Concern on the part of electric utilities in the acquisition of data from the real-time distribution system [10], together with the high number of active elements, such as DG, inserted in the networks and the diverse contributions of companies and researchers, has been leveraging program reform as well as its use throughout the world.

OpenDSS has been presented as a robust tool for analysis of distribution systems. The software can be connected with tools like MatLab, Python and others. This allows OpenDSS to become a useful tool to academic community and electric utility that are interested in developing optimization algorithms for their systems.

In addition, OpenDSS calculates the relevant parameters for the steady-state, transient, unbalanced phase circuit and can calculate the power flow with different types of simulations: snapshot, daily and yearly power flow. The instantaneous simulation mode can be used to analyze the conditions of maximum operation of the distribution system, as well as to provide information on the operating conditions of the circuit in front of the installation of new loads. The daily method is important when it is necessary to analyse the power flow at different times of the day. In this model it is necessary to supply the quantity of points that will be calculated the power flow, the interval between these points, as well as the demand curve in pu by the loadshape connected to the circuit. All of these features can be seen in [11]

In OpenDSS, it is essential to declare the circuit element. The circuit element models the transmission system and the distribution substation that is connected to the distribution network, also known as Thevenin Equivalent [12].

Below is presented an example of how the circuit element must be declared.

New circuit.alimentador $\quad$ basekv $=13.8 \quad$ Bus $1=4831863$ $p u=1.05 \mathrm{MVAsc} 3=1000000000 \mathrm{MVAsc1}=1000000000$ 
On what:

basekv : nominal voltage of the distribution network, in $\mathrm{kV}$;

Bus1 : bus that the substation is connected;

pu : substation voltage bus, in pu;

$M V A s c 3$ : three-phase short-circuit power;

MVAsc1 : single-phase short-circuit power.

After that, the other elements of the system must be declared, like: line, loads and equipment. The line element is based on pi model and an example is presented below.

New Line.L1 Phases $=3 \quad$ Bus $1=2847549.1 .2 .3$

Bus2 $=$ 2847546.1.2.3 LineCode $=39$ Length $=0.1618$

On what:

$\begin{array}{ll}\text { Phases } & \text { : number of phases in the line; } \\ \text { Bus1 } & \text { : initial bus that the line is connected; } \\ \text { Bus } 2 & \text { : final bus that the line is connected; } \\ \text { LineCode } & \text { : line geometries; } \\ \text { Length } & \text { : line length. }\end{array}$

Subsequently, the loads that model the consumers connected to the distribution system must be generated. In the daily simulation mode it is necessary a loadshape for the system loads. An example of declared load is:

New load.IT21149844 bus $1=2847552.1$ phases $=1$ conn $=$ wye model $=1 \mathrm{~kW}=34,04 \mathrm{pf}=0.92$ daily $=2095566$

On what:

$\begin{array}{ll}\text { bus } 1 & \text { : bus that the load is connected; } \\ \text { phases } & \text { : number of phases of the load; } \\ \text { conn } & \text { : connection load; } \\ \text { model } & \text { : load model (constant power, current or } \\ & \text { impedance); } \\ k W & \text { : maximum load active power; } \\ \text { pf } & \text { : power factor; } \\ \text { daily } & \text { : curve model. }\end{array}$

The focus of this papers is analyse the DG impact in a distribution system feeder, so it is necessary to model the photovoltaic generator. OpenDSS models the photovoltaic generator and frequency inverter according to Fig. 2.

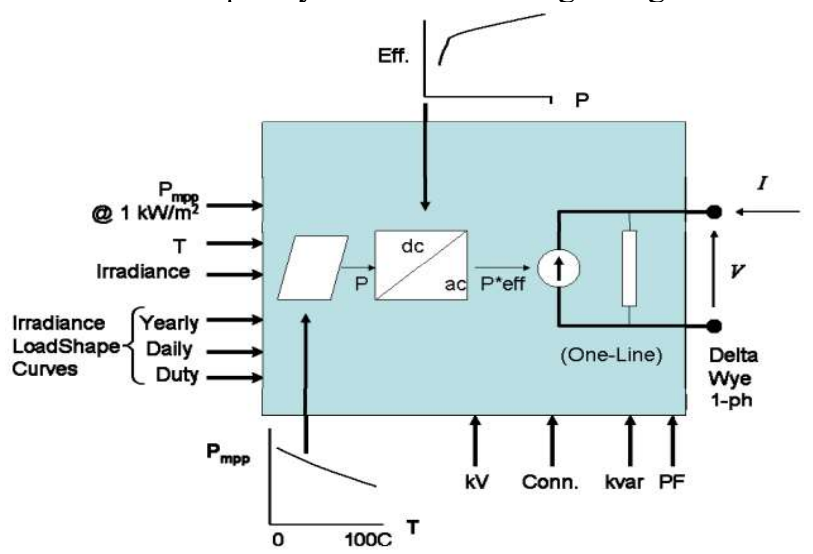

Fig.2. Model of the photovoltaic generator used in OpenDSS and all the quantities required for its declaration.
The power at the maximum power point $\left(\mathrm{P}_{\mathrm{MPP}}\right)$ is the amount of electrical power available by the module when there is an incidence of $1000 \mathrm{~W} / \mathrm{m}^{2}$ under the operation at a temperature $\mathrm{T}$. Thus, is considered that the inverter can extract the maximum values of $\mathrm{P}_{\mathrm{MPP}}$ at each instant of the simulation. This affirmative is justified because the power generated by the module will present different values in the instants that will be made the analysis. This variation occurs based on a curve that must be inserted in the OpenDSS that contains the $\mathrm{P}_{\mathrm{MPP}}$ as a function of the temperature for different points, $\mathrm{P}_{\mathrm{MPP}} \mathrm{X} \mathrm{T}$, assuming the nominal generation value at the instant that the system temperature reaches the standard.

It is essential that a second curve is also loaded in the OpenDSS, which relates the efficiency of the inverter to the power coming from the panel (Eff x P).

In addition to the above-mentioned curves, the model requires that the operating voltage of the generator be declared at the point of connection to the grid, as well as the connection mode (delta or wye), number of phases and the power factor of the system.

The power generated by the photovoltaic module is calculated according to Eq. (1).

$$
P=P_{m p p} * k_{P_{m p p} x T} * k_{\text {irrad.curve }} * I r_{\text {base }}
$$

On what:

$$
\begin{array}{cl}
P_{m p p} & : \text { maximum power; } \\
k_{P_{m p p} x T} & : \text { curve fator - Pmpp x Temperature; } \\
k_{\text {irrad.curve }} & : \text { irradiance curve factor; } \\
\text { Ir } r_{\text {base }} & : \text { base irradiance; }
\end{array}
$$

Similarly, the output power of the inverter will depend on the efficiency curve Eff $\mathrm{x}$ P, where the output power can be obtained as follows:

$$
P_{\text {out }}=\operatorname{Eff} x P
$$

In this way, in the model of the photovoltaic system, or in any other generator created in the OpenDSS, the power flow is verified in the direction of the element for the connection point with circuit remainder. This is the concept given by OpenDSS to elements that convert power (Power Conversion - PC). Distribution lines, as well as transformers, receive the definition of elements that carry power (Power Delivery - PD).

\section{Brazilian Real Feeder}

The distribution network that will be analysed in this work is the circuit of a feeder of an electric utility in Brazil. The loads connected throughout the feeder are mostly composed by consumers with a residential profile.

The data provided by the electric utility describe the medium voltage of the feeder and the information of the transformers that connect the average and the low voltage are scarce. Another difficult information in the company's database is the daily consumption profile of the consumers, which makes it necessary to use load curves typical of the consumer types to define the load curves of the distribution transformers.

In the Fig. 3 is presented the single-line diagram provided by OpenDSS of the network that represents the feeder under study. The red point represent the transformer that makes the connection between the substation and the system. 


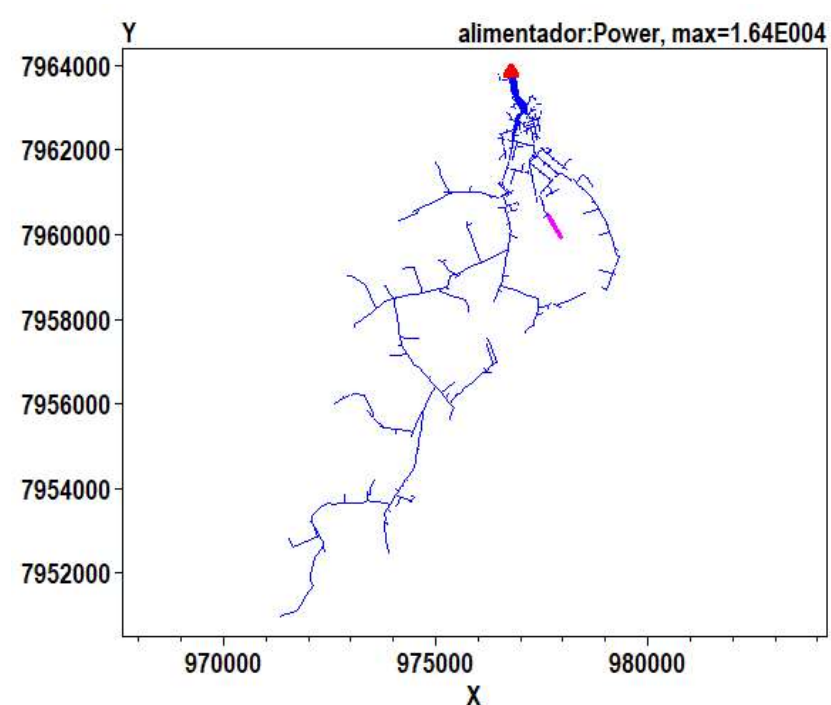

Fig.3. Single Feeder Diagram (with scale in meters)

In Table I is the general information of the analyzed feeder. It is noticed that is a large feeder, typically residential.

Tabela I . Feeder Description

\begin{tabular}{|c|r|l|}
\hline INFORMATION: & VALOR & UNIT \\
\hline Nominal voltage & 13,80 & $\mathrm{kV}$ \\
\hline Transformers & 244 & units \\
\hline Total Power Transformers & 18,79 & MVA \\
\hline Feeder Extension (Medium Voltage) & 18,50 & $\mathrm{~km}$ \\
\hline Number of Residential Consumers & 777 & units \\
\hline Number of Commercial Consumers & 257 & units \\
\hline Number of Industrial Consumers & 2 & units \\
\hline
\end{tabular}

\section{A. Consumer Load Curves}

In OpenDSS, as mentioned previously, there is the possibility of carrying out an analysi for a specific moment, as well as a daily simulation, in which case the load curves of the consumers and of the generation are necessary.

Currently, electric utilities in Brazil do not have all their consumers with electronic meters, so the only information that consumers have about their demand is monthly consumption values. So, companies carry out measurement campaigns to obtain more information about the consumption profiles of their customers. With this information, typical curves are generated by classes of consumers, such as residential, commercial and industrial. In Fig. 4 the typical daily curves, in pu, are presented for these 3 classes of consumers used in this work.

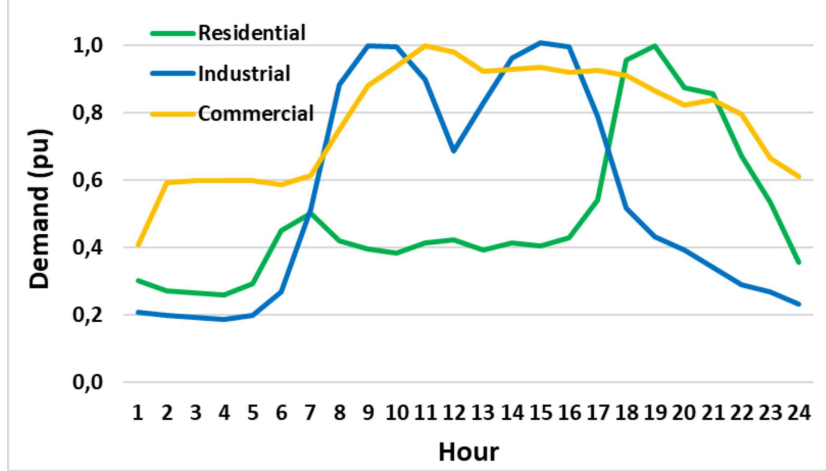

Fig. 4. Typical demand curves, in pu, used in this work.
In [13] the technique used takes the consumption ( $\mathrm{kWh}$ ) of the consumers to generate the individual curves of the consumers and consequently of the distribution transformers.

In this work, as the only information on the feeder loads was the individual power of each of the distribution transformers (MV/LV). So, it was used to define the load curves through this power and the typical load curves shown in Fig. 4.

Thus, with this limitation of the consumer data, Eq. (3) was used to determine the demand of each of the transformers for each hour of the day $\left(C_{t r}^{t}\right)$, considering the maximum demand equal to the nominal power of the equipment $\left(S_{t r}\right)$.

$$
C_{t r}^{t}=\frac{\alpha \times C_{c o m}^{t}+\beta \times C_{r e s}^{t}+\gamma \times C_{i n d}^{t}}{\alpha+\beta+\gamma} \times S_{t r}
$$

On what:

$$
\begin{array}{cl}
\alpha & : \text { Number of commercial consumers; } \\
\beta & : \text { Number of residential consumers; } \\
\gamma & : \text { Number of industrial consumers; } \\
\mathrm{t} & : \text { instants of the curve }(\mathrm{t}=1, \ldots, 24) ; \\
C_{\text {com }}^{t} & : \text { Demand of the typical commercial curve (in pu); } \\
C_{\text {res }}^{t} & : \text { Demand of the typical residential curve (in pu); } \\
C_{\text {ind }}^{t} & : \text { Demand of the typical industrial curve (in pu). }
\end{array}
$$

Thus, the mainstream is to model all loads attached to a transformer as a single load with a demand curve only. The curves are generated based on curves typical of the company and that tend to approach the reality, which makes the analyses more realistic.

\section{Results}

The feeder was analysed using two scenarios of the photovoltaic distributed generation insertion in the feeder. Below are both scenarios and their comparisons. In Fig. 5 is shown the feeder demand curve after the modeling of the transformer curves and the generation curves for the scenarios.

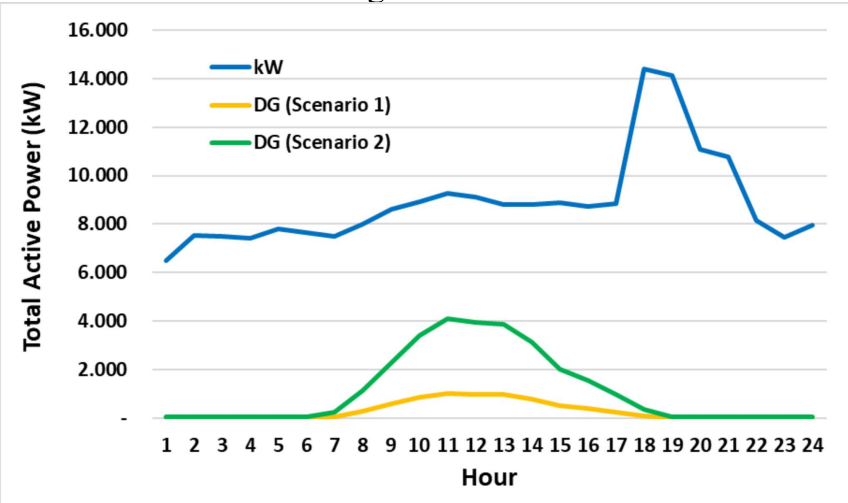

Fig.5. Demand curve of the analysed feeder.

As was opted for a daily analysis, it is important to note that the maximum feeder demand is $14.39 \mathrm{MW}$ and occurs at $6 \mathrm{pm}$, and the daily consumption is approximately $213.85 \mathrm{MWh}$. The maximum generation occurs at $11 \mathrm{am}$, for both scenarios.

\section{A. Scenario 1}

In the first analysis were inserted DG near the substation and at the end of the feeder, where the largest voltage drops are verified. 
For this scenario, 7 photovoltaic generators with the following characteristics were considered:

- All three-phase generators with nominal voltage of $380 \mathrm{~V}$ and unit power factor;

- 4 generators with a maximum power of $100 \mathrm{~kW}$ each on;

- 1 generator with a maximum power of $200 \mathrm{~kW}$;

- 1 generator with a maximum power of $250 \mathrm{~kW}$;

- 1 generator with a maximum power of $300 \mathrm{~kW}$.

The insertion points of these generators, the nominal power of the distribution transformers at the insertion point was considered as the limit.

The total power of the panels inserted in this first scenario is $1.15 \mathrm{MWp}$ (Mega Watt-peak), which represents $12.4 \%$ of the feeder's demand $(9.27 \mathrm{MW})$ at $11 \mathrm{am}$, as can be seen in the demand curve presented previously (Fig. 5).

\section{B. Scenario 2}

To verify the behavior of the loss indices and voltage in the actual feeder studied, a second analysis was performed. Considering that it is an extensive urban feeder, with a total of 18.5 kilometers of medium voltage lines, a considerable increase of distributed generation photovoltaic was analysed. Thus, a generation of $4.6 \mathrm{MWp}$, which is equivalent to $49.6 \%$ of the total feeder power without the GD at $11 \mathrm{am}$. So, was considered the insertion of 7 new generators in the feeder besides those that were inserted in Scenario 1, totaling 14 generators. The points of the new generators was performed at random.

It should be noted that the new photovoltaic generators inserted and those already present in Scenario 1 were declared with a power two times higher than the values of Scenario 1, which results in $4.6 \mathrm{MWp}$.

In Fig. 6 is shown the single-line diagram of the system and the location of the photovoltaic generators inserted for both scenarios.

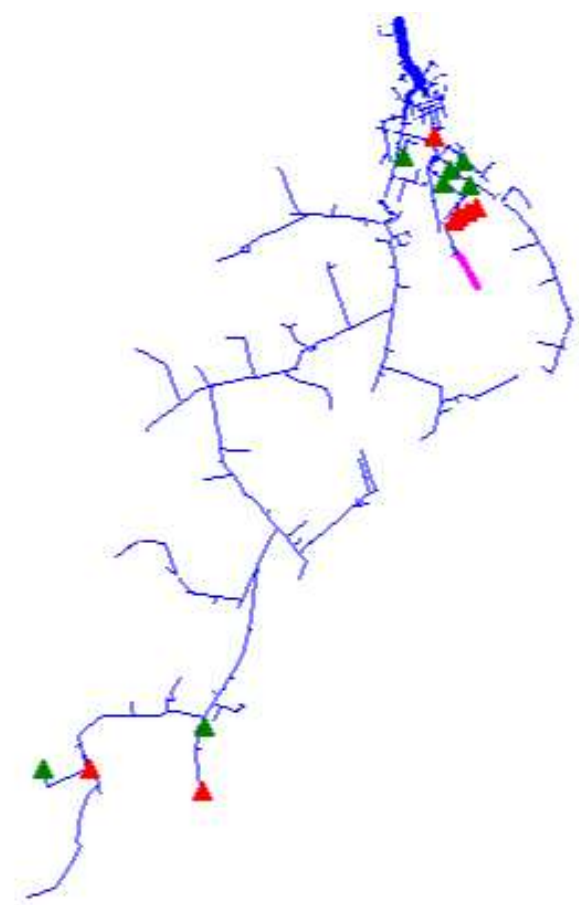

Fig. 6. Feeder with GD - Scenario 1 (red) and Scenario 2 (red + green)

\section{Scenario $1 \times$ Scenario 2}

In order to verify the behavior of the loss levels during the day, the active losses in $\mathrm{kW}$ along the day are presented in Fig. 7.

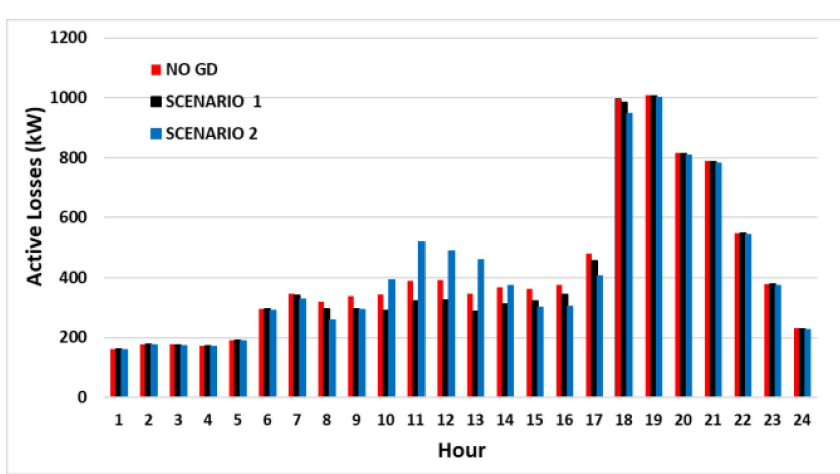

Fig. 7. Comparison of losses for the different scenarios.

In Scenario 1, it can be observed that there was a reduction of losses, especially in the period when there is a higher solar incidence (between 10 am and $2 \mathrm{pm}$ ). In Scenario 2, in moments of maximum solar incidence, the losses increase considerably in relation to the other two scenarios (without DG and Scenario 1). Such an increase can be justified mainly by the reverse power flow, which also culminates in the increase of the voltage in the bus, outside the limit specified in ANEEL (National Electric Energy Agency) Distribution Procedures, Module 8 (PRODIST) [14].

Considering energy losses in daily $\mathrm{kWh}$, in the case where there is no distributed generation in the feeder, losses are approximately $10 \mathrm{MWh}$, while for Scenarios 1 and 2, they are approximately 9.51 MWh and 9.98 MWh, respectively. Representing a reduction of $4.9 \%$ for Scenario 1 and $0.2 \%$ for Scenario 2.

It should also be noted that in both cases a unit power factor was considered for all frequency inverters. Thus, outside the hours of maximum solar incidence, 10 am to 2 p.m., the losses related to the highest generation case are the lowest. This is explained by the efficiency curve of the panel loaded in the OpenDSS, which defines how much electrical power is converted from $1000 \mathrm{~W} / \mathrm{m}^{2}$ of incidence, $\mathrm{P}_{\mathrm{mpp}}$, as presented above.

In addition to temperature being a determining factor in the design of this curve, it is considered in the adopted frequency inverter model that for operating conditions outside the nominal the DC/AC conversion efficiency also decreases.

Thus, both efficiencies give rise to a power in the generators that when injects in the system culminates in the reduction of the losses outside the peak hours. In the graphs of Fig. 8, 9 and 10 the system voltage levels are presented for the cases: without DG, scenario 1 and scenario 2, respectively. It was considered the moment of higher system demand (6 pm).

The voltage levels are shown according to the distance of the bus to the feeder substation. For all cases, a voltage of 1.05 pu was considered in the substation. 


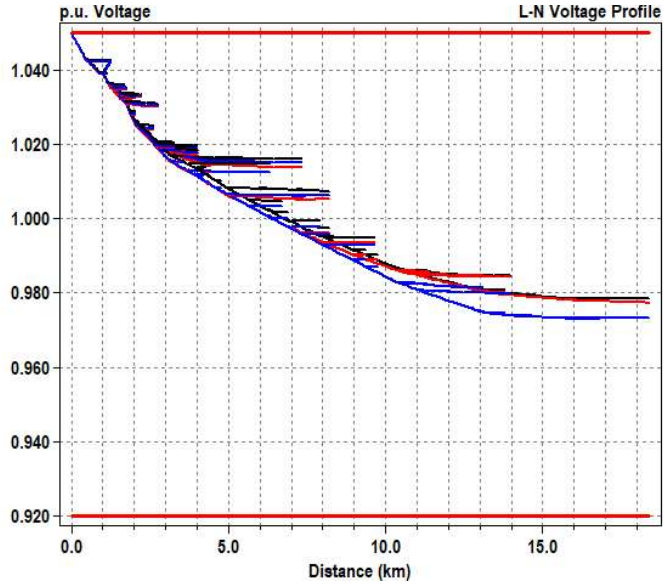

Fig. 8. Voltage levels for the system without DG in maximum demand.

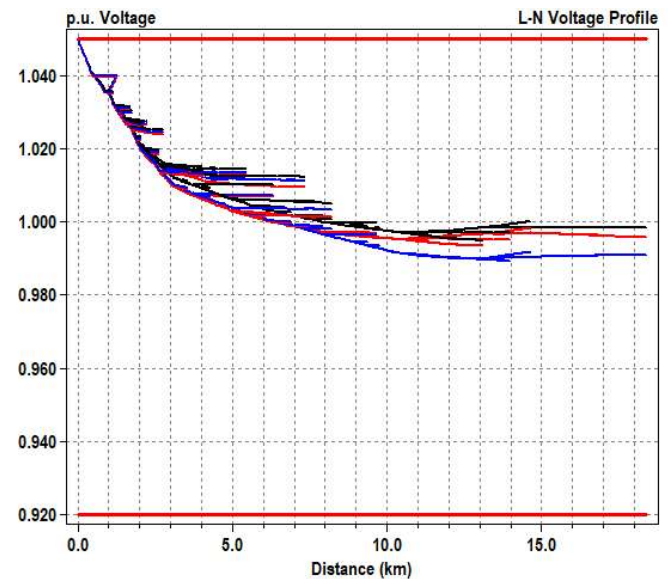

Fig. 9. Voltage levels for Scenario 1 in maximum demand.

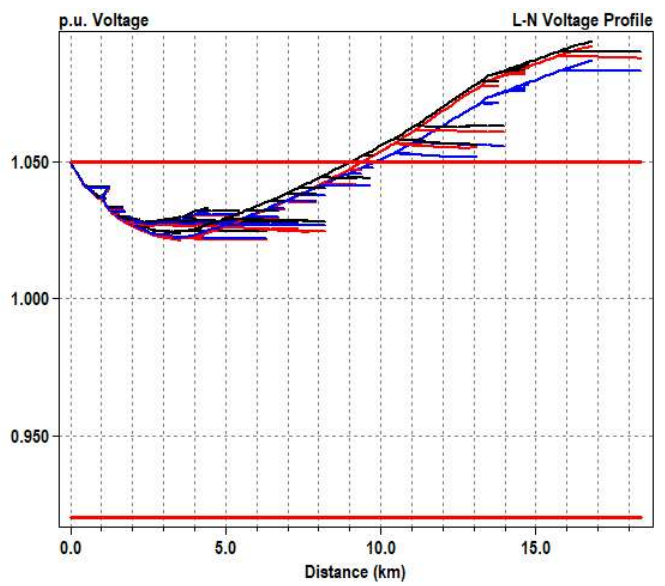

Fig. 10. Voltage levels for Scenario 2 in maximum demand.

Note that for the system without distributed DG there was a voltage drop of approximately $7.60 \%$. When inserting the photovoltaic generation of $5.71 \%$ into the system (Scenario 1) it is possible to verify (Fig. 9) that there was an improvement in the network voltage levels. However, with a considerable increase in this generation (Scenario 2) there were severe transgressions in the voltage levels, as can be seen in Fig. 10.

\section{Conclusions}

In this work, a real system of distribution with and without distributed generation using OpenDSS software was used as support. The adoption of OpenDSS was followed using the criterion that the software is free and recommended by ANEEL in the calculation of electrical losses in distribution systems. The authors point out that the analyzes performed were only possible due to the use of free software such as OpenDSS.

The losses of the system with and without the insertion of the distributed generation were shown, highlighting that part of these losses are intrinsic to the circuit, since they have their origin in transformers and distribution lines. In this sense, for the two scenarios shown it was verified that with a generation of 1.15 MWp, the losses were all lower when compared to the system without generation.

In the following situation, generation of $4.6 \mathrm{MWp}$, the results showed that the losses are the highest in the moments of maximum incidence and the lowest in the moments of lower incidence.

Therefore, it is concluded that in the near future the insertion of DG will cause serious consequences to the feeders and with that, one must initiate discussions about the Brazilian regulations, that is, these analyses are important to the utilities and regulators to define actions in that they touch the considerable increase of DG in the distribution systems.

\section{References}

[1] Agência Nacional De Energia Elétrica - ANEEL, Geração distribuída - Brasil ultrapassa marca de $1 \mathrm{GW}$ em geração distribuída: Regulamentos da Agência possibilitaram avanço da geração distribuída, 2019. Available in: < http://www.aneel.gov.br/>.

[2] Agência Nacional De Energia Elétrica - ANEEL, Resolução n. 505 de 26 de novembro de 2001, Brasília (2001), 14p.

[3] International Energy Agency - IEA, "Distributed Generation in Liberalised Electricity Markets.”, OECD Publishing (2002), 124p.

[4] T. Ackermann, G. Andersson, and L. Sode, "Distributed generation: A definition," Electric Power Systems Research (2001), v. 57, p. 195204.

[5] A. K. Singh and S. K. Parida, "Novel sensitivity factors for dg placement based on loss reduction and voltage improvement," Electrical Power and Energy Systems (2016), v. 74, p. 453-456.

[6] Agência Nacional De Energia Elétrica - ANEEL, Banco de Informações de Geração, 2019. Available in: $<$ http://www2.aneel.gov.br/aplicacoes/capacidadebrasil/capacidadebra sil.cfm>.

[7] K. M. Santos, A. N. Souza, D. S. Gastaldello, C. C. O. Ramos and P. Costa Júnior, "Development of an Algorithm to Determine Load Curves from Possession and Consumption Habits for Consumers: Residential, Commercial and Industrial." SBSE - Brazilian Symposium on Electrical Systems (2012), Goiânia, Brazil.

[8] J. J. F. Blatt, "Proposta de instalação de regulador de tensão em uma rede de distribuição primária a partir da análise do perfil de tensão," Northwestern Regional University of the Rio Grande do Sul (2016), Santa Rosa, RS, Brazil, 2016.

[9] M. A. S. Masoum, M. Ladjevardi, A. Jafarian, and E. F. Fuchs, "Optimal placement, replacement and sizing of capacitor banks in distorted distribution networks by genetic algorithms", IEEE Transactions On Power Delivery (2004), v. 19, i.4.

[10] H. Farhangi. "The Path of the Smart Grid," IEEE Power and Energy Magazine (2010), v. 8., issue 1.

[11] Sourceforge, "Opendss Software Manual", 2019. Available in: $<\mathrm{https}: / /$ sourceforge.net/projects/electricdss/>

[12] P. Radatz, Advanced models of analysis of intelligent electrical networks using OpenDSS software, Sao Paulo University (2016), Sao Paulo, Brazil, 191p.

[13] A. A. Francisquini, Estimation of load curves at consumption points and distribution transformers. State University of São Paulo (2006), Ilha Solteira, Sao Paulo, Brazil, 108p.

[14] Agência Nacional De Energia Elétrica - ANEEL, PRODIST Distribution procedures. Module 8: quality of the electric energy. Brasilia (2018), Brazil, 88p. 